\title{
Contemporary Overview on Assessing and Treating Children
}

\section{Mohammad Qasem Abdullah*}

Counseling \& Clinical Psychology. Faculty of Education, University of Aleppo, Syrian Arab Republic, Syria

*Corresponding author: Mohammad Qasem Abdullah, Counseling \& Clinical Psychology. Faculty of Education, University of Aleppo, Syrian Arab Republic, Syria

\section{Abstract}

Conducting psychotherapy research with children, raises many difficulties and question should be confronted and answered. The aim of this article is to highlight on the clinical and critical issues in assessing and treating children from developmental and psychopathological perspective.

Keywords: Clinical issues, abnormal behavior, assessment, children

\section{Mini Review}

Assessing children and adolescents is challenging. Generally, the child/adolescent in question would not have initiated the consultation or may not be in agreement with the need for a consultation. The consultation may or may not even be sought for the most impairing problem at hand. While children may be able to report the nature of symptoms, they may not be very good at reporting the timing and duration of their problems [1]. They may not report problems if they are embarrassing or show them in a bad light. Clinical assessments with children and adolescents are, therefore, elaborate and require the clinician to be astute and conscientious in obtaining information from multiple sources and settings, i.e., the child, parents, teachers, and other caregivers [2]. Many questions should be answered when assessing children in clinical practice: the most significant question is relating to understanding a child's silence during assessment and treatment. The following indexes represent the most important answers to this challenge Table 1 [3].

The course of normal development and the delineation of dysfunction have been poorly understood. This issue need to be considered in designing individual treatment investigations and in evaluating the therapy outcome studies. The central goal of a clinical assessment is to come to a case formulation that would guide management decisions [3]. Delineating signs and symptoms through detailed clinical history and examination help ascertain key areas of concern
Table 1: Indexes of the silence of children during assessment.

\begin{tabular}{|c|c|}
\hline \multicolumn{2}{|c|}{ Why children won't talk? } \\
\hline 1 & Anxiety \\
\hline 2 & anger \\
\hline 3 & developmental deficits \\
\hline 4 & Physiological need (hunger, sleep) \\
\hline 5 & Mental disorders \\
\hline
\end{tabular}

and presence (or absence) of a mental health disorder. To adequately comprehend the origins, maintenance, and factors affecting remission from the disorder, it is essential to place the child within a psychosocial background, relate the presentation to his/her unique context, and to gather details about what has happened to the illness so far, including what has been the treatment and response history. According to the (DSM-V), the diagnostic system relied upon clinical observations to identify diagnostic entities. The dimensions arising in multivariate analysis with frequently associated characteristics of each as presented in Table 2 [4].

The significant issues for the treating child are: first to whom the child should be referred and directed, second, the diversity of the person and specialists should be involved for treating, third, whether treatment should be administrated by the clinicians directly to the child, individual or group therapy [4]. 
Table 2: Dimensions arising in multivariate analysis with frequently associated characteristics of each.

\begin{tabular}{|c|c|}
\hline Conduct disorders & Socialized aggression \\
\hline Hitting, fighting & Has bad companion \\
\hline Disobedient, defiant & Truant from home \\
\hline Destructiveness & Belong to a gang \\
\hline Temper tantrums & Loyal to delinquent friends \\
\hline Uncooperative, resistant & Steals in company of others \\
\hline \multicolumn{2}{|l|}{ Impertinent. } \\
\hline Attention problems & Schizoid-unresponsive \\
\hline Poor concentration & Will not talk \\
\hline Short attention span & Sad \\
\hline Day dreaming & Confused \\
\hline Impulsive & Withdrawn \\
\hline Clumsy, poor coordination & Stars blankly \\
\hline \multicolumn{2}{|l|}{ Preoccupied } \\
\hline \multicolumn{2}{|l|}{ Fails to finish tasks } \\
\hline Motor over activity & $\begin{array}{c}\text { Anxious- Depressed } \\
\text { withdrawal }\end{array}$ \\
\hline Overactive, restless & Anxious, fearful, tense \\
\hline Excitable, impulsive & Shy, timid \\
\hline Over talkative & Depressive, sad \\
\hline \multirow[t]{2}{*}{$\begin{array}{l}\text { Hams and makes other odd } \\
\text { noises }\end{array}$} & Hypersensitive, easily hurt \\
\hline & Feels inferior, woethles. \\
\hline
\end{tabular}

\section{Conclusion}

Developmental changes have raised a variety of dilemma and issues in assessing and treating child and adolescent. child and adolescent mental health shares close links with other medical specialties such as neurology and pediatrics while being rooted in the child's psychosocial environment and experience $[5,6]$. Assessment of children and adolescents must evolve from a biopsychosocial perspective, taking into account these inextricably interlinked aspects. Clinical history taking and interviewing are one of the most powerful tools available to the child and adolescent mental health professional to make a diagnosis and plan management. It is very important to use multi-methodology for investigating the effectiveness of assessment and treatment approach during childhood and adolescent, such as development longitudinal, experimental, clinical and case-studies for good understanding, predicting and controlling the abnormal behavior.

\section{References}

1. King RA (1997) Practice parameters for the psychiatric assessment of children and adolescents. American Academy of Child and Adolescent Psychiatry. J Am Acad Child Adolesc Psychiatry 36: 4S-20S.

2. Leckman JF, Taylor E (2015) Clinical assessment and diagnostic formulation. In: Thapar A, Pine DS, Leckman JF, Scott S, Snowling MJ, Taylor E, editors. Rutter's Child and Adolescent Psychiatry. ( $6^{\text {th }}$ edn), Chichester, West Sussex, Ames, John Wiley \& Sons Inc, Iowa, USA.

3. Srinath S, Jacob P, Sharma E, Gautman A (2019) Clinical practice guidelines for assessing children and adolescents. Indian Journal of Psychiatry 61(2): 158-176.

4. Abdullah M (2016) Psychological and behavioral problems of children. University of Aleppo press. Syria.

5. Abdullah M (2018) Significance of multi-procedures for assessing and treating children. Clinical Neuroscience \& Neurological research International Journal 1(1): 180005.

6. Abdullah QM (2019) Introduction to mental health. Amman: Dar-Alfikr.

*Corresponding author: Mohammad Qasem Abdullah, Email: mk.abdalah@yahoo.com

Next Submission with BGSR follows:

- Rapid Peer Review

- Reprints for Original Copy

- E-Prints Availability

- Below URL for auxiliary Submission Link: https://biogenericpublishers.com/submit-manuscript/ 